\title{
Technology Roadmapping Application in Smart City's Development
}

\author{
Sameh M SAAD ${ }^{\mathrm{a}, 1}$, Ramin BAHADORI ${ }^{\mathrm{a}}$, Hongwei $\mathrm{ZHANG}^{\mathrm{a}}$ and Abdulaziz \\ ALBAQAMI $^{\mathrm{a}}$

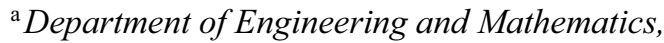 \\ Sheffield Hallam University, Howard Street, Sheffield S1 1WB, UK
}

\begin{abstract}
Modern cities are changing to become more reliant upon technology for better personal, social, and economic outcomes for all citizens. The core of enabling a smart city plan relies on a comprehensive understanding of its drivers and technological aid requirements. Hence, technology roadmapping as one of the most effective approaches need to be considered to aligning the smart cities strategies with planning in the field of technology, while the focus on the most technology roadmapping studies has been limited to the development of industrial technology and product development. Thus, to support the achievement of the smart cities, this study aims to adapt and utilise Strategic Technology Alignment Roadmapping (STAR) methodology to guid and justify investment in smart city's R\&D projects to achieve the optimum project portfolio. The method is tested in a real case study, which shows how STAR methodology can be effective to implement throughout the worldwide smart cities development to support strategic technology investments.
\end{abstract}

Keywords. Technology roadmapping, R\&D projects, smart city.

\section{Introduction}

Today's world-class businesses face many challenges, including the rapid development of technologies, rapid changes in market situations, the complexity of the products, short product life cycle, production with the lowest cost and the constant demands of customers for quality products and global competition [1,2, and 3]. Hence, the development of adapted technologies with the enterprise needs is well understood as the key solution to increase the competitiveness and survival of a company or even an industry [4]. In such a context, ensuring the application of proper technologies to maximise the company's profits is the primary objective of any technology management. Technology managers always need to be sure the existing and potential technologies of the organisation are in line with its current and future goals [5]. Technology roadmapping (TRM), a strategic decision process framework that supports enterprise innovation activities is the well-known approach to effective technology management and planning

\footnotetext{
${ }^{1}$ Corresponding Author. S. Saad@shu.ac.uk
} 
which highly can increase the competitiveness capabilities in the growing world of technology. It was first introduced and developed by Motorola in 1978 to achieve integrated product-technology planning [6,7]. A technology roadmapping is the part of a methodology that guarantees the alignment of investment in technology, the development of its capabilities and the ability to meet future market needs [8]. The world technology is progressing at incredible speeds, and the market demand for manufactured goods has been shifted to more integrated solutions [9]. Focusing solely on physical goods cannot create a sustainable competitive advantage for manufacturing firms, and this has led firms to create a new source for value creation [10,11]. Many manufacturers have shifted their focus from the business model of merely selling goods or services to the solution provider model [12]. This global trend is described in the literature as "Servitization", which was first introduced by [13] has been widely recognised as a mechanism to add new value to products by adding services [14]. Despite this global trend, the focus on technology roadmapping studies has been limited to the development of industrial technology and product development, and there is very little research has been carried out to apply the TRM as a paradigm to the service area $[15,16]$. Therefore, this research aims to utilise Strategic Technology Alignment Roadmapping (STAR) methodology [17] to develop smart city's R\&D projects. STAR ${ }^{\circledR}$ was initially designed and tested successfully to optimise the R\&D investments in the manufacturing processes of large and high-tech enterprises like in aerospace [18] and then it has proven to be worthwhile for SME's [19]. But, in this research, the STAR $₫$ methodology is adapted for first time to aligning city council R\&D activities to its business and service vision through identifying, selecting, prioritising and developing technologies to satisfy stakeholder's needs at all stages of urban development, smart city drivers and technology competitiveness position. In this paper, the focus is on the Riyadh city council and the suburbs to achieve the optimum project portfolios among the smart city development projects.

\section{Application of STAR ${ }^{\circledR}$ in smart city development projects}

The implementation of the STAR processes was started by scheduling a series of initial meetings with the Riyadh city council's senior managers to decide upon the objective of this practice, the participants and the formation of teams. In the preliminary stage, the generic STAR framework is adapted towards the Riyadh smart city development (see Figure 1). In addition, technical data, including smart city drivers, their related actions and technologies for demonstration targets were collected. 


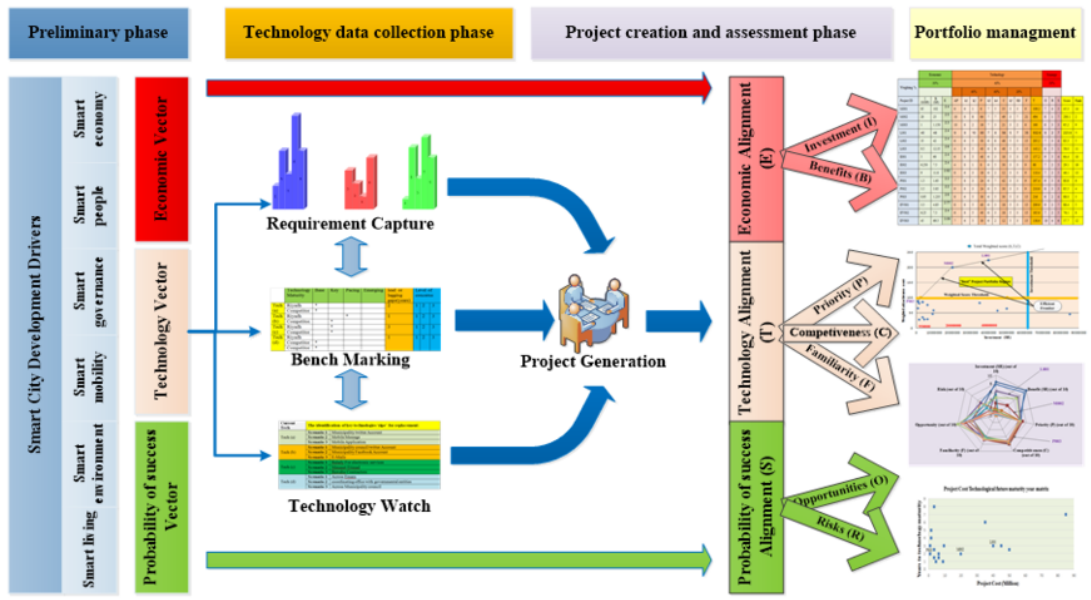

Figure 1: The adaption of the STAR generic framework towards the Riyadh smart city development

Then, in the next workshops, during the technology data collection phase, the following exercises were completed, and outputs were transmitted to the next stage.

- As part of the requirements capture process, Analytic Hierarchy Process (AHP) was utilised to provide both the action and technology priorities. The output of this step later contributes to the project assessment phase in the form of the action priority (AP) and technology priority (P) factors.

- To assess the city of Riyadh competitive position in a range of relevant technologies, a technology benchmarking exercise is carried out using a graphical interface that enables the users to select the technology to be considered and evaluated under its competitive position in terms of technology maturity (base, key, dynamic and emerging). In this case, the city of Jeddah was considered the main competitor by Riyadh's mayor. The technology benchmarking provides input in the form of a level of concern factor at the project assessment phase.

- At the end of the technology requirements phase, the recognised technologies through previous steps including both state-of-the-art and emerging technologies, are evaluated based on their potential opportunities or threats using technological threats and opportunity analysis (TTOA). For more detail see [20]. The output of this step is considered as an input to the project assessment phase in the form of a technology threat/opportunity factor for each technology.

Next, at the beginning of the project creation and assessment phase, before the project generation is started, assessment settings of projects were adjusted by city council top managers to reflect enterprise preferences. Adjusting the project assessment settings guarantees that projects that are matched with the Riyadh city council's technology requirements are rated to be higher than those that are not.

Later, during the project generation, as given in table 1, a set of 18 projects has been created and covered the most areas of smart cities development of interest. The project proposal sheets plus project proposal forms were considered to be input to the project assessment phase. 
Table 1: List of generated project proposals

\begin{tabular}{lll}
\hline Smart City Components & Project ID & \multicolumn{1}{c}{ Project description } \\
\hline \multirow{3}{*}{ Smart Mobility } & M001 & Tram System project \\
\cline { 2 - 3 } & M002 & A bike-sharing scheme in Riyadh: hire-able bikes \\
\cline { 2 - 3 } Smart Living & M003 & Electric vehicles replace petrol vehicles \\
\cline { 2 - 3 } & L001 & Leisure places and sports facility \\
\cline { 2 - 3 } S002 & Public parks \\
\hline \multirow{3}{*}{ Smart Economy } & E001 & Entertainment City \\
\cline { 2 - 3 } Smart People & E002 & Smart metres \\
\cline { 2 - 3 } & E003 & Circular Economy \\
\hline \multirow{3}{*}{ Smart Environment } & P001 & Free Wi-Fi Internet Access in Public Places \\
\cline { 2 - 3 } & P002 & The Electronic Health Record (EHR) \\
\cline { 2 - 3 } & P003 & E-Learning and The Modern Education System \\
\hline \multirow{3}{*}{ Smart Governance } & EV002 & Modern waste-to-energy plants \\
\cline { 2 - 3 } & EV003 & Green electricity \\
\cline { 2 - 3 } & G001 & Renewable Energy \\
\hline & G002 & Gourt Digital Case System \\
\hline & G003 & Online Payment Gateway \\
\hline
\end{tabular}

As part of the project assessment, the total weighted score of each project (project attractiveness) is calculated with the assessor's team. As shown in Table 2, the Leisure places and sports facility project (L001) received the highest rank (223.5), followed by the bike-sharing scheme in Riyadh: hire-able bikes (M002) (200.075) and E-Learning and the Modern Education System (P003) (87.99) and Online Payment Gateway and Government Gateway (G003 \& G002) were the least rankings (28.7865 \& 27.75) respectively.

Table 2: Project proposal assessment calculation

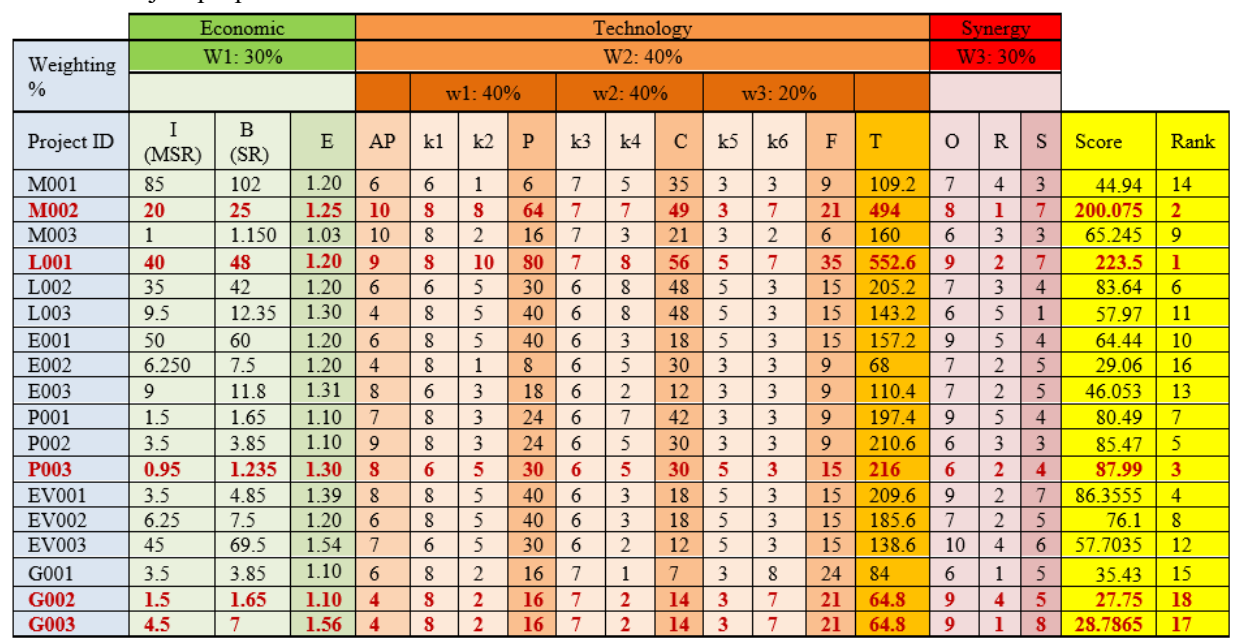




\section{Conclusion}

In this study, the STAR methodology was adapted and utilised to guide and justify investment in smart city $R \& D$ projects to achieve the optimum project portfolio. The STAR methodology was implemented at Riyadh city council as a case study. The STAR was started with intensive workshops with a group of city council-managers from different levels and departments to identify the smart city drivers and technology requirements, assess city competitive position in a range of relevant technology, and identify technologies that may replace current city technologies. Then, potential project portfolios were created and evaluated to determine the high-rank projects through three factors; an economic factor which determines the financial investment and benefits, the technological factor, which indicates the availability of required technology means to achieve defined outcomes and the synergy factor for identifying the opportunities and risks of the project.

\section{References}

[1] I. Pentina, D. Strutton, Information processing and new product success: a meta-analysis, European Journal of Innovation Management 10(2) (2007), 149-75.

[2] C. Lofdahl, M. Voshell, and S. Mahoney, Designing Future Processing, Exploitation, and Dissemination Support Systems Using Simulation, Procedia Computer Science 36 (2014), 33-40.

[3] M. Arab Zozani, S. Bagheri Faradonbeh, and E. Jaafari Pooyan, The Role of health technology assessment in improving healthcare quality, Journal of Payavard Salamat 9(4) (2015), 400-414.

[4] M. Gerdsri, An analytical approach to building a technology development envelope (TDE) for roadmapping of emerging technologies, International Journal of Innovation and Technology Management 4(02) (2007), 121-135.

[5] H. Martin, \& T.U. Daim, Technology roadmap development process (TRDP) for the service sector: A conceptual framework, Technology in Society 34(1) (2012) 94-105.

[6] R. Phaal, C.J. Farrukh, and D.R. Probert, Technology roadmapping - a planning framework for evolution and revolution, Technological forecasting and social change 71(1-2) (2004), 5-26.

[7] J.H. Lee, R. Phaal, and C. Lee, An empirical analysis of the determinants of technology roadmap utilization, $R \& D$ Management 41(5) (2011), 485-508.

[8] R. Phaal, C.J.P. Farrukh, and D.R. Probert,.Fast-start technology roadmapping. In Proceedings of the 9th International Conference on Management of Technology, 2000, 21-25.

[9] C. Gustafsson, K. Chirumalla, and G. Johansson, Application of lean methods and tools in servitization: A literature review. In ISPIM Innovation Symposium, 2018, 1-17. The International Society for Professional Innovation Management (ISPIM).

[10] R. Oliva, and R. Kallenberg, Managing the transition from products to services, International journal of service industry management 14(2) (2003), 160-172.

[11] T. Brady, A. Davies, and D.M. Gann, Creating value by delivering integrated solutions, International Journal of Project Management 23(5) (2005), 360-365.

[12] A. Bikfalvi, G. Lay, S. Maloca, and B.R. Waser, Servitization and networking: large-scale survey findings on product-related services Service Business 7(1) (2013), 61-82.

[13] S. Vandermerwe, and J. Rada, Servitization of business: adding value by adding services. European management journal 6(4) (1988), 314-324

[14] F. Sánchez - Montesinos, M. Opazo Basáez, D. Arias Aranda, and O.F. Bustinza, Creating isolating mechanisms through digital servitization: The case of Covirán, Strategic Change 27(2) (2018), 121-128

[15] J.H. Suh, and S.C. Park, Service-oriented Technology Roadmap (SoTRM) using patent map for R\&D strategy of service industry, Expert Systems with Applications 36(3) (2009), 6754-6772

[16] J.H. Lee, R. Phaal, and S.H. Lee, An integrated service-device-technology roadmap for smart city development, Technological Forecasting and Social Change 80(2) (2013), 286-306

[17] N. Gindy, M. Morcos, B. Cerit, and A. Hodgson, Strategic technology alignment roadmapping STAR® aligning R\&D investments with business needs, International Journal of Computer Integrated Manufacturing 21(8) (2008), 957-970. 
[18] N. Gindy, B. Cerit, and A. Hodgson, Technology roadmapping for the next generation manufacturing enterprise, journal of manufacturing technology management 17(4) (2006), 404-416.

[19] N. Gindy, H. Arman, and S. Cavin, Linking R\&D investment strategies to business needs: Strategic Technology Alignment Roadmapping (STAR). In Portland International Conference on Management of Engineering \& Technology, 2009, 2455-2465. IEEE.

[20] H. Arman, and J. Foden, Combining methods in the technology intelligence process: application in an aerospace manufacturing firm, R\&d Management 40(2) (2010), 181-194. 